\title{
Wet Cupping's Effect on Nitric Oxide Levels in Hypertensive Patients
}

\author{
Sharlini Desfika ${ }^{1,2}$, Muhammad Ichwan ${ }^{1,3}$, Dedi Ardinata ${ }^{1,4 *}$ (D) \\ ${ }^{1}$ Master Program in Biomedical Sciences, Faculty of Medicine, Universitas Sumatera Utara, Medan, Indonesia; ${ }^{2}$ Department of \\ Physiology, Faculty of Medicine, Universitas Muhammadiyah Sumatera Utara, Medan, Indonesia; ${ }^{3}$ Department of Pharmacology \\ and Therapeutics, Faculty of Medicine, Universitas Sumatera Utara, Medan, Indonesia; ${ }^{4}$ Department of Physiology, Faculty of \\ Medicine, Universitas Sumatera Utara, Medan, Indonesia
}

Edited by: Sinisa Stojanosk Citation: Desfika S, Ichwan M, Ardinata D. Wet Cupping's Effect on Nitric Oxide Levels in Hypertensive Patients. OpenAccess MacedJ $/$ do Wet cupping: Nitric oxide; Blood pressure ${ }^{*}$ Correspondence: Dedi Ardinata, Department of
Coret Physiology, Faculty of Medicine, Universitas Sumatera Utara, Medan, Indonesia. E-mail: dedi1@usu.ac.id Received: 27-Dec-202 Revised: 12-Jan-2022 Copyright: ๑ 2022 Sharlini Desfika, Muhammad Ichwan, Dedi Ardinata Funding: SD receives funding partially from the Faculty Medan, Indonesia, in completing thesis research.
of Medicine, Universias Muhammadiyah Sumatera Utara, Medan, Indonesia, in completing thesis research
Competing Interests: The authors have declared that no Open Access: This is an open-access article distributed under the terms of the Creative Commons AttributionNonCommercial 4 . International License (CC BY-NC 4.0)

\begin{abstract}
BACKGROUND: Wet cupping is a non-pharmacological therapy that has been shown to assist hypertensive patients with blood pressure reduction. However, the underlying mechanisms by which wet-cupping lowers blood pressure are currently unknown. More scientific investigation is necessary to explain the mechanism by which wet cupping lowers blood pressure, particularly the role of nitric oxide (NO).

AIM: The study aimed to show the effect of wet cupping on NO levels in hypertensive patients.

METHODS: A pre-experimental study using a single group pre-test and post-test design to monitor changes in blood NO levels and blood pressure in 45 hypertensive patients in Medan after 4 weeks of wet cupping therapy. The patients' blood NO levels, as well as their systolic and diastolic blood pressures (SBP and DBP), were measured before and after 4 weeks of wet cupping.

RESULTS: After 4 weeks of wet cupping, blood NO levels significantly increased $(0.00704 \mathrm{~mol} / \mathrm{mL}, p=0.039)$, while SBP and DBP levels significantly decreased $(12.644 \mathrm{mmHg}$ and $7.111 \mathrm{mmHg}$, respectively, $\mathrm{p}<0.001)$. However, there was no correlation between increased blood NO levels and reductions in SBP and DBP ( $p=0.468$ and $p=0.299$, respectively).

CONCLUSION: This study found that after 4 weeks of cupping therapy, the decrease in SBP and DBP was not accompanied by an increase in blood NO levels.
\end{abstract}

\section{Introduction}

The World Health Organization (WHO) estimates that 1.4 billion people worldwide have high blood pressure [1]. The prevalence of hypertension sufferers in Indonesia in 2018 reached 658,201 people $(8.84 \%)$, North Sumatra province reached 41,382 people $(6.07 \%)$, and the city of Medan reached 7174 people $(5.17 \%)$ [2]. Physiological blood pressure regulation requires a complex interaction of several components of the integrated neurohumoral system, including the reninangiotensin-aldosterone system (RAAS), natriuretic peptides, endothelium, sympathetic nervous system (SNS), and immune system. Disruption of the factors that control blood pressure in any component of this integrated neurohumoral system over time can cause an increase in mean blood pressure, blood pressure variability, or both, resulting in damage to target organs such as left ventricular hypertrophy and chronic renal failure, which can cause cardiovascular diseases [3].

Hypertension must be managed with both pharmacological and non-pharmacological therapy. Nonpharmacological therapy helps lower the daily dose of antihypertensive medications and delays the development of hypertension. Non-pharmacological therapy involves lifestyle changes, such as diet modification, exercise, stress avoidance, and alcohol consumption reduction [4]. One of the present non-pharmacological therapeutic approaches is complementary and alternative medicine (CAM), such as cupping [5]. Cupping has been shown to improve immunity by increasing the number of natural killers cells, lowering the clinical index of rheumatoid arthritis, and reducing the severity of fibromyalgia pain, headaches and migraines, and hypertension [6], [7], [8].

The benefits of wet cupping on hypertension have been demonstrated by a significant difference in systolic blood pressure (SBP) on day 42 after three sessions of wet cupping separated by 2 weeks in a group of hypertensive patients with no history of other chronic diseases [9]. Another study found that wet cupping was significantly effective in lowering blood pressure, both systolic and diastolic, in hypertensive patients at the $4^{\text {th }}$ week after wet cupping, which was performed 3 times on the $17^{\text {th }}, 19^{\text {th }}$, and $21^{\text {st }}$ of the lunar calendar, while there was no significant difference at the $8^{\text {th }}$ week [10]. Wet cupping also affects baroreceptors, which are indicators of blood pressure decrease, as evidenced by a significant difference in systolic and diastolic blood pressure in hypertensive patients at 
weeks 2 and 4 , but no significant difference at week 6 after wet cupping for the 1 time on the $17^{\text {th }}, 19^{\text {th }}$, and $21^{\text {st }}$ of the lunar calendar [11]. Despite the empiric benefit of wet cupping therapy in hypertension, the underlying mechanism by which wet-cupping lowers blood pressure is unknown.

Nitric oxide (NO) has a physiological effect, particularly on smooth muscle relaxation, by activating the NO/cyclic guanosine monophosphate pathway. The role of $\mathrm{NO}$ in the cardiovascular system is being studied, particularly in NO-deficient hypertension models where NO production is inhibited by NG-nitro-Larginine methyl ester (L-NAME), which non-specifically inhibits all isoforms of the nitric oxide synthase (NOS) enzyme. NOS inhibition has been shown to reduce blood flow in humans and increase blood pressure and vasoconstriction in animals. NO is determined by the amount of nitrate $\left(\mathrm{NO}_{3}^{-}\right)$and nitrite $\left(\mathrm{NO}_{2}\right)$ content in plasma. The mechanism of NO production is dependent on the action of endothelial NOS (eNOS) on L-arginine in endothelial cells [12], [13]. Reduced NO bioavailability, especially in renal circulation, has been identified as a major factor in the pathogenesis of hypertension [14].

Hypertensive patients had lower plasma NO levels than normotensive patients (77.2 $33.2 \mathrm{~mol} / \mathrm{L}$ vs. $88.040 \mathrm{~mol} / \mathrm{L}, \mathrm{p} 0.001$ ), according to a previous study [15]. Another study found a significant difference in serum NO levels in normotensive and hypertensive men (111.713.52 mol/mL vs. $95.293 .04 \mathrm{~mol} / \mathrm{mL}, \mathrm{p} 0.001$ ) [16].

The mechanism of wet cupping in reducing blood pressure in hypertension is still unclear, especially the role of NO. Therefore, we studied wet cupping's influence on $\mathrm{NO}$ levels in patients with hypertension.

\section{Methods}

This experimental study used a preexperimental research design using a one-group pre-test and post-test design in three sub-district health centers in the Medan city area from October to November 2021. Criteria for inclusion are restricted to patients: (1) Men and women under 70 years old; (2) those who have primary hypertensive with SBP $140-180 \mathrm{mmHg}$ and/ or diastolic blood pressures (DBP) 90-110 mmHg; (3) subjects who have already stopped using drugs or supplements that affect blood pressure for 4 weeks; and (4) subjects who have not received cupping therapy or other CAM in the previous 8 weeks. On the other hand, the exclusion criteria include; (1) those who used non-steroidal anti-inflammatory drugs, corticosteroids, sympathomimetic drugs (decongestants, diet pills, and cocaine), stimulant drugs (methylphenidate, dexmethylphenidate, dexamphetamine, amphetamine, methamphetamine, and modafinil), oral estrogen contraception, and hormone replacement therapy while under observation; (2) those who took herbal supplements that affect blood pressure such as ginseng, guarana, and bitter orange (Citrus aurantium) as well as energy drinks; and (3) subjects who received cupping therapy or other CAM during the observation period.

The sample size was calculated using G*Power 3.1.9.2 [17], with effect size $=0.5$; $\alpha$ err prob. $=0.05$ and Power (1- $\beta$ err prob.) $=0.95$, using the mean difference test in one group before and after treatment (matched pairs) with a one-way hypothesis test (one tail) obtained a total sample of 45 people.

The overall sample included 45 hypertension patients who were selected using the consecutive sampling method. The Health Research Ethics Commission of the Faculty of Medicine, Universitas Sumatera Utara, Indonesia, approved the study protocol (No: 1057/KEP/USU/2021). This experiment was carried out by the principles of the Helsinki declaration (Edinburgh 2000 Version). The study's participation was entirely voluntary. Before the research method began, each individual signed an informed consent form.

The wet cupping procedure was carried out by paramedics who have attended standardized training and are certified by the Indonesian Cupping Association (Perkumpulan Bekam Indonesia, PBI). Single wet cupping treatment was performed on the following three points: (i) below the skull bone at the hairline, just two fingers behind the lower jaw angle on both sides (Al-Akhda'ain); (ii) the upper spine that connects to the spine and neck, the upper third of the spine consists of six vertebrae or cervical vertebrae C7 (Al-Kaahil); and (iii) shoulder blades on both sides (Azh-Zahrul A'la) (Figure 1) [11].

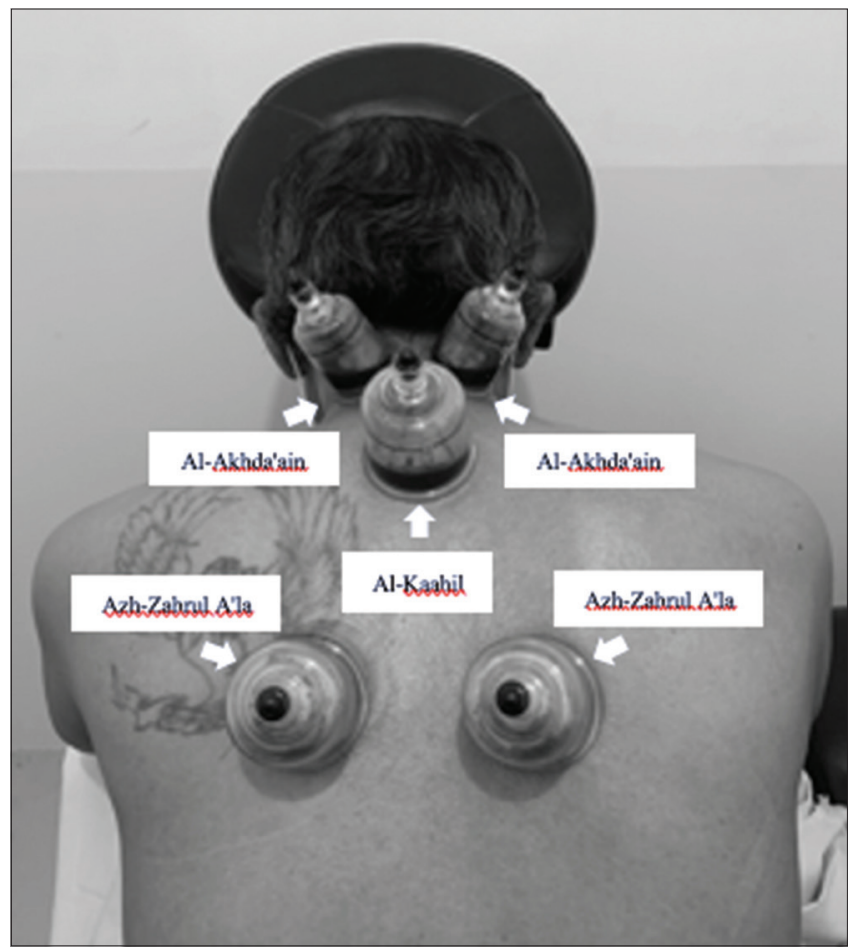

Figure 1: Wet cupping points (Photograph courtesy of Wahida Clinic Medan) 
Blood NO level was measured before too and after 4 weeks of wet cupping by the Content Assay Kit (Solarbio $^{\circledR}$, Beijing, China), catalog number BC1475. About $3 \mathrm{~mL}$ of venous blood was taken using a VACUETTE. Then, it was centrifuged at 3000 rotations/ $\min$ for $15 \mathrm{~min}$ at a temperature of $4^{\circ} \mathrm{C}$ and the blood serum was taken and put in storage in a refrigerator at $-80^{\circ} \mathrm{C}$ until the sample size was sufficient for NO examination. Blood pressure was measured before too and after 4 weeks of wet cupping, while sitting in a quiet room, using the digital sphygmomanometer (Omron $^{\circledR}$, HEM-7156, Japan) which has been calibrated by the Medan Health Facility Security Agency (Balai Pengamanan Fasilitas Kesehatan, BPFK). The blood pressure procedure follows the National Heart Foundation of Australia's 2016 guidelines for the diagnosis and management of hypertension in adults. There was no change in hypertension treatment during observation in all subjects. The $\mathrm{IBM}^{\circledR}$ SPSS $^{\circledR}$ statistics software version 23 for Window ${ }^{\circledR}$ was used to analyze the data and $p<0.05$ was considered statistically significant.

\section{Results}

This study enrolled 45 subjects who met the eligibility criteria. About 29 (64.4\%) of the subjects were female. The majority were between the ages of 40 and 65 (35 [77.8\%] subjects). About 18 (40\%) subjects did not receive treatment for hypertension (Table 1).

Table 1: Baseline characteristics of research subjects

\begin{tabular}{|c|c|c|}
\hline Characteristics & Total $(\mathrm{n})$ & Percentage \\
\hline \multicolumn{3}{|l|}{ Gender } \\
\hline Male & 16 & 35.6 \\
\hline Female & 29 & 64.4 \\
\hline \multicolumn{3}{|l|}{ Age } \\
\hline$<40$ years old & 1 & 2.2 \\
\hline 40-65 years old & 35 & 77.8 \\
\hline$>65$ years old & 9 & 20 \\
\hline \multicolumn{3}{|l|}{ Ethnicity } \\
\hline Aceh & 1 & 2.2 \\
\hline Batak & 5 & 11.1 \\
\hline Javanese & 6 & 13.3 \\
\hline Mandailing & 11 & 24.4 \\
\hline Malay & 3 & 6.7 \\
\hline Minangkabau & 19 & 42.2 \\
\hline \multicolumn{3}{|c|}{ Treatment of hypertension } \\
\hline Amlodipin $5 \mathrm{mg}$ & 17 & 37.8 \\
\hline Amlodipin $10 \mathrm{mg}$ & 9 & 20.0 \\
\hline Nifedipine $10 \mathrm{mg}$ & 1 & 2.2 \\
\hline Not any & 18 & 40.0 \\
\hline \multicolumn{3}{|c|}{ Use of antihypertensive drugs } \\
\hline Regular & 13 & 28.9 \\
\hline Irregular & 14 & 31.1 \\
\hline Not use & 18 & 40.0 \\
\hline
\end{tabular}

A paired t-test revealed a statistically significant $(p=0.039)$ increase in mean blood NO level of $0.00704 \mathrm{~mol} / \mathrm{mL}$ after 4 weeks of wet cupping (Figure 2).

A paired t-test revealed a significant decrease in mean SBP of $12.644 \mathrm{mmHg}(p<0.001)$ and a significant decrease in mean DBP of $7.111 \mathrm{mmHg}$ $(p<0.001)$ (Figure 3).

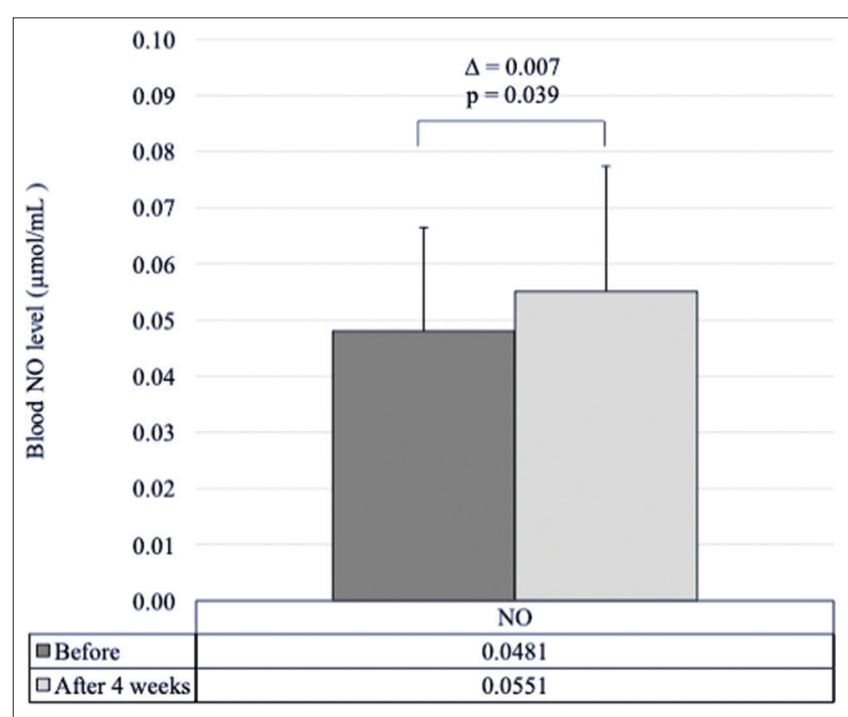

Figure 2: Comparison of blood Nitric oxide level

Pearson correlation test revealed a nonsignificant $(p=0.468)$ relationship between increasing blood NO levels and decreasing SBP, as well as a nonsignificant $(p=0.299)$ relationship between increasing blood NO levels and decreasing DBP (Table 2).

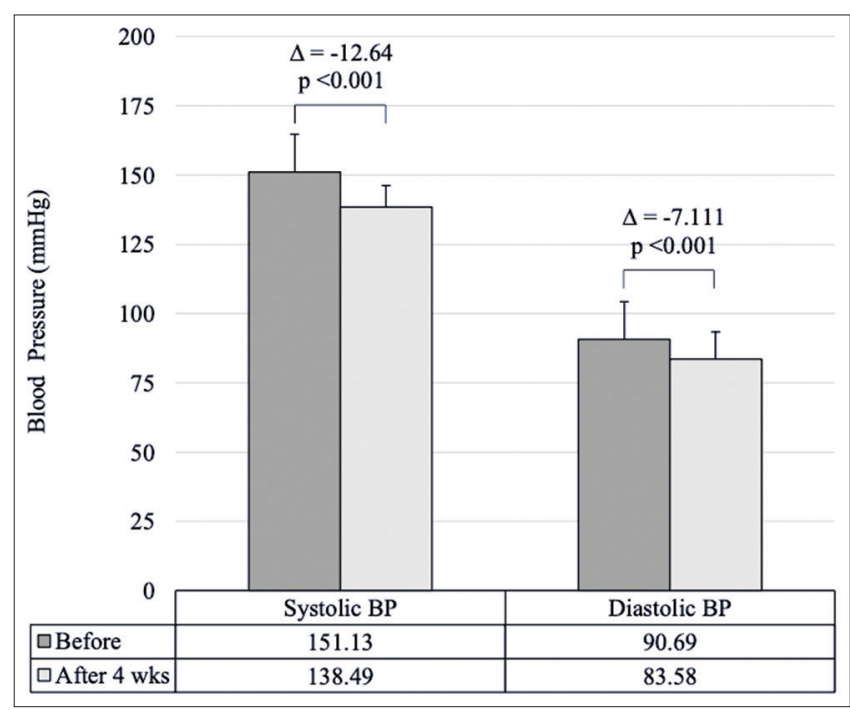

Figure 3: Comparison of systolic blood pressure and diastolic blood pressure

\section{Discussion}

One or more theories can partially explain the therapeutic effects of wet cupping: Muscle relaxation, specific changes in local tissue structure, and increased blood circulation can be explained by the release of the NO theory. The activation of the immune system theory can explain the increase of the immune system and hormonal changes that are more related to anti-inflammatory effects. The release 
of toxins, uric acid, lipoproteins, serum glutamic oxaloacetic transaminase, iron, and heavy metals can be explained as follows the blood detoxification theory [18]. The "release of NO and enhanced blood circulation theory" explains how cupping therapy can induce NO release from endothelial cells. The expression of NOS, the enzyme that produces NO from L-Arginine, was higher around acupoints in rat skin in one experiment [19].

Table 2: Correlate between increased levels of NO with a decrease in systolic and diastolic blood pressure after 4 weeks of wet cupping

\begin{tabular}{lll}
\hline Correlate & $r$ & $p$ \\
\hline NO levels - Systolic blood pressure & -0.012 & 0.468 \\
NO levels - Diastolic blood pressure & -0.081 & 0.299 \\
\hline NO: Nitric oxide. & &
\end{tabular}

Endogenous NO production has been reported to increase during skin and wound healing after injury. Vascular endothelial growth factor (VEGF) increases NO production through upregulation of eNOS during wound repair. In contrast, the angiogenic effect of VEGF is also NO-dependent because pharmacological blockade of NOS prevents VEGF and mitogen-activated protein kinase-induced endothelial cell proliferation [20], [21]. This shows that NO can be produced locally on the wounded skin during the wet cupping treatment, as seen by a significant increase in blood NO levels $(0.00704 \mathrm{~mol} / \mathrm{mL}, \mathrm{p}=0.039)$ in this study after 4 weeks of wet cupping (Figure 2). Wet cupping therapy can reduce oxidative stress in healthy adults, according to the Tagil et al., as shown by blood in cupping healthy subjects having higher NO levels than venous blood $(p=0.007)$ and a positive association $(r=0.64, p=0.001)$. Wet cupping's mechanism of action is not completely understood. Wet cupping may influence oxidative equilibrium, according to the study [22].

Wet cupping's mechanism for lowering blood pressure was not understood fully. According to the Taibah's theory, wet cupping removes interstitial fluid, decreasing excess intravascular fluid and other toxic metabolites. According to this theory, wet cupping stimulates the production of endogenous $\mathrm{NO}$ as well as the removal of vasoactive chemicals and free radicals, all of which can help reduce blood pressure [23].

This study found a significant decrease in SBP of $12.644 \mathrm{mmHg}(p<0.001)$ and a significant decrease in DBP of $7.111 \mathrm{mmHg}(p<0.001)$ (Figure 3). Several prior studies have demonstrated the efficacy of wet cupping in the management of hypertension. Zarei et al., 2012, reported a significant decrease in SBP $(p<0.05)$ in hypertensive patients after 42 days of wet cupping [9]. Aleyeidi et al., 2015, conducted a randomized controlled trial (RCT) that resulted in a significant decrease in SBP $(p=0.046)$ but an insignificant decrease in DBP $(p=0.681) 4$ weeks after wet cupping, and an insignificant differentiation in both SDP and DBP ( $p=0.129$ and $p=0.881)$ after 8 weeks of wet cupping [10]. A significant decrease in SBP and DBP in elderly hypertensive patients after 2 -4 weeks of wet cupping $(p<0.001)$ was associated with an increase in arterial baroreflex sensitivity, but a decrease in SBP and DBP was not significant after 4-6 weeks of cupping $(p=0.267$ and $p=0.771)[11]$.

Reduced NO levels were associated with improvements in clinical indicators in the previous investigations (systolic, diastolic, and mean arterial blood pressure). ADRB2 and NOS3 gene expression was reduced in hypertension patients and there was a definite correlation between genotype and NO levels. Variants of these two genes interact to impair the vasodilation response, resulting in elevated blood pressure associated with the pathophysiology of hypertension. This is consistent with the theory that gene-environment interactions were a key to the development of hypertension and other complex disorders [15].

There was no significant $(p=0.468)$ correlation between increased blood NO levels and lower SBP and DBP in this study (Table 2). The findings of this investigation revealed that the reduction in SBP and DBP after 4 weeks of wet cupping was unrelated to the role of blood NO levels. Although the relationship was not significant, there was a statistically significant increase in blood NO levels. This may be because the examination of blood NO levels is not immediately checked after wet cupping. The decrease in SBP and DBP is probably due to one or more interacting factors: (1) The RAAS [24], (2) natriuretic peptide involvement [25], (3) the endothelium [26], (4) the SNS [27], (5) immune system [28], and (6) baroreceptor sensitivity [29]. Fadli et al., 2020, demonstrated that wet cupping therapy can significantly lower blood pressure and heart rate in hypertensive elderly adults by stimulating autonomic nerves and preserving baroreceptor sensitivity for 4 weeks [11].

There were some limitations to this study. This is a single-center investigation; however, to confirm the primary findings, a multi-center clinical trial will be conducted. To provide further validation of our findings, RCTs with sham groups will be performed. At the present, our focus is showed the level of NO in the blood. Furthermore, it is critical to recognize and understand the role of other mediating factors. Furthermore, the study required the reporting of adverse events as well as other periods for follow-up and therapy; larger studies with long-term monitoring could contribute to the development of a standardized wet cupping treatment procedure.

\section{Conclusion}

In patients with hypertension, wet cupping therapy increased blood NO levels while lowering systolic and diastolic blood pressure. However, there is 
no significant correlation between blood NO level and blood pressure changes.

\section{References}

1. Guideline for the Pharmacological Treatment of Hypertension in Adults. Geneva: World Health Organization; 2021.

2. The Ministry of Health of the Republic of Indonesia. Riskesdas 2018 Report. Jakarta: Research and Development Agency, Ministry of Health; 2019.

3. Hall ME, Hall JE. Pathogenesis of hypertension. In: Bakris GL, Sorrentino MJ, editoes. Hypertension: A Companion to Braunwald's Heart Disease. $3^{\text {rd }}$ ed. Netherlands: Elsevier; 2018. p. 33-51. https://doi.org/10.1016/B978-0-323-42973-3.00005-6

4. Mahmood S, Shah KU, Khan TM, Nawaz S, Rashid H, Baqar SW, et al. Non-pharmacological management of hypertension: In the light of current research. Irish J Med Sci. 2019;188(2):437-52. https://doi.org/10.1007/s11845-018-1889-8 PMid:30136222

5. Wang J, Xiong X. Evidence-based Chinese medicine for hypertension. Evid Based Complement Alternat Med. 2013;2013:978398. https://doi.org/10.1155/2013/978398 PMid:23861720

6. Ahmed SM, Madbouly NH, Maklad SS, Abu-Shady EA Immunomodulatory effects of blood letting cupping therapy in patients with rheumatoid arthritis. Egypt J Immunol. 2005;12(2):39-51.

PMid:17977209

7. Ahmadi A, Schwebel DC, Rezaei M. The efficacy of wetcupping in the treatment of tension and migraine headache. Am J Chin Med. 2008;36(1):37-44. https://doi.org/10.1142/ S0192415X08005564

PMid: 18306448

8. Cao H, Hu H, Colagiuri B, Liu J. Medicinal cupping therapy in 30 patients with fibromyalgia: A case series observation. Forschende Komplementarmedizin. 2011;18(3):122-6. https:// doi.org/10.1159/000329329

PMid:21701180

9. Zarei M, Hejazi S, Javadi SA, Farahani H. The efficacy of wet cupping in treatment of hypertension. Arya Atherosc. 2012;8:316.

10. Aleyeidi NA, Aseri KS, Matbouli SM, Sulaiamani AA, Kobeisy SA Effects of wet-cupping on blood pressure in hypertensive patients: A randomized controlled trial. J Integ Med. 2015;13(6):391-9. https://doi.org/10.1016/S2095-4964(15)60197-2 PMid:26559364

11. Fadli F, Ahmad A, Baharuddin R, Februanti S. Effect of wet cupping against increased arterial baroreflex sensitivity in hypertensive patients: Randomized controlled trial (RCT). J Crit Rev. 2020;7:671-6. http://doi.org/10.31838/jcr.07.14.118

12. Víteček J, Lojek A, Valacchi G, Kubala L. Arginine-based inhibitors of nitric oxide synthase: Therapeutic potential and challenges. Mediators Inflamm. 2012;2012:318087. https://doi. org/10.1155/2012/318087 PMid:22988346

13. Ahmad A, Dempsey SK, Daneva Z, Azam M, Li N, Li P, et al. Role of nitric oxide in the cardiovascular and renal systems. Int J Mol Sci. 2018;19(9):2605. https://doi.org/10.3390\%2Fijms19092605 PMid:30177600

14. Rajapakse NW, Mattson DL. Role of cellular L-arginine uptake and nitric oxide production on renal blood flow and arterial pressure regulation. Curr Opin Nephrol Hypertension. 2013;22(1):45-50. https://doi.org/10.1097/MNH.0b013e32835a6ff7

PMid:23095292

15. Kumar R, Kohli S, Mishra A, Garg R, Alam P, Stobdan T, et al Interactions between the genes of vasodilatation pathways influence blood pressure and nitric oxide level in hypertension. Am J Hypertension. 2014;28(2):239-47. https://doi.org/10.1093/ ajh/hpu130

PMid:25159081

16. Aflyatumova GN, Nigmatullina RR, Sadykova DI, Chibireva MD, Fugetto F, Serra R. Endothelin-1, nitric oxide, serotonin and high blood pressure in male adolescents. Vasc Health Risk Manage. 2018;14:213-23. https://doi.org/10.2147/vhrm.s170317 PMid:30271160

17. Franz F, Erdfelder E, Lang AG, BuchnerA. G*Power 3.1 (manual): A flexible statistical power analysis program for the social, behavioral, and biomedical sciences. Behav Res Methods. 2007;39(2):175-91. https://doi.org/10.3758/bf03193146 PMid: 17695343

18. Al-Bedah AM, Elsubai IS, Qureshi NA, Aboushanab TS, Ali GI, Elolemy AT, et al. The medical perspective of cupping therapy: Effects and mechanisms of action. J Tradit Complement Med. 2018;9(2):90-7. https://doi.org/10.1016/j.jtcme.2018.03.003 PMid:30963043

19. Ma SX. Enhanced nitric oxide concentrations and expression of nitric oxide synthase in acupuncture points/meridians. J Alternat Complement Med. 2003;9(2):207-15. https://doi. org/10.1089/10755530360623329

PMid: 12804074

20. Frank S, Kämpfer $\mathrm{H}$, Wetzler $\mathrm{C}$, Pfeilschifter J. Nitric oxide drives skin repair: Novel functions of an established mediator. Kidney Int. 2002;61(3):882-8. https://doi. org/10.1046/j.1523-1755.2002.00237.x PMid:11849442

21. Luo J, Chen AF. Nitric oxide: A newly discovered function on wound healing. Acta Pharmacol Sin. 2005;26(3):259-64. https:// doi.org/10.1111/j.1745-7254.2005.00058.x PMid: 15715920

22. Tagil SM, Celik HT, Ciftci S, Kazanci FH, Arslan M, Erdamar N, et al. Wet-cupping removes oxidants and decreases oxidative stress. Complement Ther Med. 2014;22(6):1032-6. https://doi. org/10.1016/j.ctim.2014.10.008 PMid:25453524

23. El Sayed SM, Mahmoud HS, Nabo MM. Medical and scientific bases of wet cupping therapy (Al-hijamah): In light of modern medicine and prophetic medicine. Alternat Integ Med. 2013;2(5):1-16. http://doi.org/10.4172/2327-5162.1000111

24. Abdel Ghafar MT. An overview of the classical and tissue-derived renin-angiotensin-aldosterone system and its genetic polymorphisms in essential hypertension. Steroids. 2020;163:108701. https://doi.org/10.1016/j. steroids.2020.108701

PMid:32717198

25. Rubattu S, Forte M, Marchitti S, Volpe M. Molecular implications of natriuretic peptides in the protection from hypertension and target organ damage development. Int J Mol Sci. 2019;20(4):798. https://doi.org/10.3390/ijms20040798

PMid:30781751

26. Tomiyama $\mathrm{H}$, Ishizu $\mathrm{T}$, Kohro $\mathrm{T}$, Matsumoto $\mathrm{C}$, Higashi $\mathrm{Y}$, Takase B, et al. Longitudinal association among endothelia function, arterial stiffness and subclinical organ damage in hypertension. Int J Cardiol. 2018;253:161-6. https://doi. org/10.1016/j.ijcard.2017.11.022

PMid:29174285 
27. Manta E, Konstantinidis D, Dimitriadis K, Tatakis F, Drogkaris S, Polyzos $\mathrm{D}$, et al. Correlations between sympathetic nervous system activity and smoking, as well as unattended blood pressure in essential hypertension. Eur Heart J. 2021;42:2599. https://doi.org/10.1093/eurheartj/ehab724.2599

28. Caillon A, Paradis P, Schiffrin EL. Role of immune cells in hypertension. Br J Pharmacol. 2019;176(12):1818-28. https:// doi.org/10.1111/bph.14427

PMid:29952002

29. Li C, Chang $Q$, Zhang J, Chai W. Effects of slow breathing rate on heart rate variability and arterial baroreflex sensitivity in essential hypertension. Medicine. 2018;97(18):e0639. https:// doi.org/10.1097\%2FMD.0000000000010639

PMid:29718876 